\title{
La crisis del mercado de crédito y sus consecuencias.
}

\author{
Victórico Rubio González \\ Profesor Asociado Universidad Autónoma de Madrid
}

\section{INTRODUCCIÓN}

Desde mediados de 2007, el sistema financiero ha entrado en una crisis sistémica cuyo epicentro se encuentra en los mercados de crédito. La crisis crediticia actual tuvo su origen en el deterioro del mercado de hipotecas de alto riesgo en EEUU (Subprime Mortgage Lending). Si bien desde un principio se consideró que la crisis estaba localizada en este segmento del mercado hipotecario norteamericano, conforme se han ido desarrollando los acontecimientos en los últimos trimestres, se ha puesto de manifiesto que el problema no es tan sencillo. La crisis crediticia se ha extendido tanto a numerosas áreas del sector financiero, como de la economía real. La economía mundial se encuentra significativamente apalancada respecto a los estándares históricos. Corregir las tendencias actuales de endeudamiento requiere la adopción de medidas estructurales que signifiquen un cambio en la forma de proceder en los negocios. Los cambios que se determinen deberían llevar a las economías a un período de transición y ajuste, que podría durar años. Los procesos de desapalancamiento requieren tiempo, al significar el reconocimiento de que hemos anticipado crecimiento futuro, a través de un endeudamiento excesivo. A lo largo de las siguientes páginas se tratará de hacer un planteamiento de los orígenes de la crisis, de la situación en la que nos encontramos y de las posibles consecuencias que de ella se pueden derivar.

\section{CONDICIONANTES ECONÓMICO-FINANCIEROS PARA LA CRISIS}

Podríamos remontarnos bastantes años para localizar el germen de la crisis financiera, ya que el desarrollo de determinados productos de crédito que están afectando de manera determinante en la actual crisis (Asset Back Securities por ejemplo) empezaron 
a desarrollarse en la década de los ochenta, sin embargo, nos centraremos en los factores que han llevado a la situación actual a hacerse insostenible. Para una mejor comprensión se ha considerado realizar un desglose entre factores económicos y de índole estrictamente financiera, ambos estrechamente relacionados.

\subsection{Condicionantes económicos}

Para la primera crisis de principios del siglo XXI, la «burbuja» en la cotización de las empresas tecnológicas en EEUU, podría considerarse un antecedente económico. El proceso inversor que impulsó la expansión tecnológica de finales de los 90 y principio del 2000 supuso un exceso de planta a escala mundial en distintas áreas de los sectores productivos: como fue el de las empresas tecnológicas (dot-com companies) o las telecomunicaciones. Las expectativas de beneficios generadas por estas empresas provocaron un exceso de oferta, que en un entorno cada vez más globalizado presionó al nivel general de precios a la baja; generando expectativas desinflacionistas. La solución de la crisis pasaba por dos posibilidades: bien dejar que se produjera el ajuste de planta «natural», es decir ajuste por el lado de la oferta, o provocar un incremento de la demanda, que permitiera un ajuste paulatino en los sectores que lo precisaran. La segunda opción fue la elegida por la mayoría de las economías representativas, canalizando la intervención a través de laxas políticas monetarias y fiscales. Sirva como ejemplo, que el estímulo conjunto - fiscal y monetario_ para la economía de los EEUU fue el más importante en magnitud del siglo Xx. La etapa comprendida entre finales de 2002 hasta 2005 estuvo caracterizada por la puesta en marcha de políticas reflacionistas con tipos de interés bajos, tanto nominales como reales y de otras medidas que favorecieron la reconstrucción de balances por parte de las empresas.

\subsection{Condicionantes financieros}

La relajación de las condiciones financieras por el descenso de los tipos de interés supuso una reactivación de las inversiones en los mercados financieros a partir de finales del año 2002. Los mercados de renta variable retomaron la senda alcista, mientras que los mercados de renta fija, tanto corporativa como del tesoro, mantuvieron un buen comportamiento soportados por la presión a la baja de los precios de consumo y las medidas fiscales adoptadas por el gobierno de los EEUU en materia de amortizaciones aceleradas. Dichas medidas permitieron que los bonos corporativos descontaran positivamente un rápido ajuste de balances 
en las compañías. La caída en los tipos de interés y el estrechamiento de los diferenciales de los bonos corporativos respecto a tesoros tuvieron consecuencias financieras y económicas positivas. Desde el punto de vista económico, la relajación de condiciones financieras vía tipos de interés se tradujo en estímulo de los sectores más sensibles a tipos de interés como es el caso del sector de construcción. De esta forma se estimuló la demanda, justo cuando el problema era de oferta. Por otro lado, el reducido retorno de los activos de renta fija hacía necesaria cada vez más necesaria la búsqueda de productos con más margen. Este factor fue determinante para el impulso que se observó en la industria de productos estructurados, en la titulización y en el proceso de desintermediación financiera.

El desarrollo de la titulización puede situarse en los años 80 o incluso antes. No obstante, a efectos de tratar de dar explicación a la crisis financiera, deberíamos centrarnos en los años 2002 y 2003, en los que las expectativas de una potencial deflación dejaron deprimidas las rentabilidades de la deuda, tanto de los bonos del Tesoro como de la deuda corporativa. En este contexto, resulta evidente que la búsqueda del margen debía acometerse desde distintas vertientes. Por un lado, supuso comenzar a titulizar activos de deuda de menor calidad crediticia con un mayor diferencial respecto a los títulos del Tesoro, entre los que se encontraban los préstamos hipotecarios de alto riesgo de impago, subprime. Por otro lado, se dio un impulso al mercado de titulización a través de un desarrollo adicional de los mercados de derivados de crédito, aprovechando una laxitud legislativa que se derivaba de un espíritu de la ley que se apoyaba en la autorregulación como forma de abordar la gestión del riesgo de las entidades financieras.

Antes de entrar en la discusión de los factores catalizadores de la crisis, vamos a describir brevemente en qué consiste una titulización y las ventajas que tiene para emisores e inversores.

\section{3. ¿Qué es una titulización?}

Titulizar consiste en convertir un derecho de cobro en un título (según Martín Abascal y Guash, 2002). En la titulización se agrupa una cartera de préstamos de características homogéneas en una sociedad que se constituye con el objeto de realizar esta función emitiendo simultáneamente unos títulos garantizados por dichos préstamos. 
Figura 1. Estructuración de la titulización

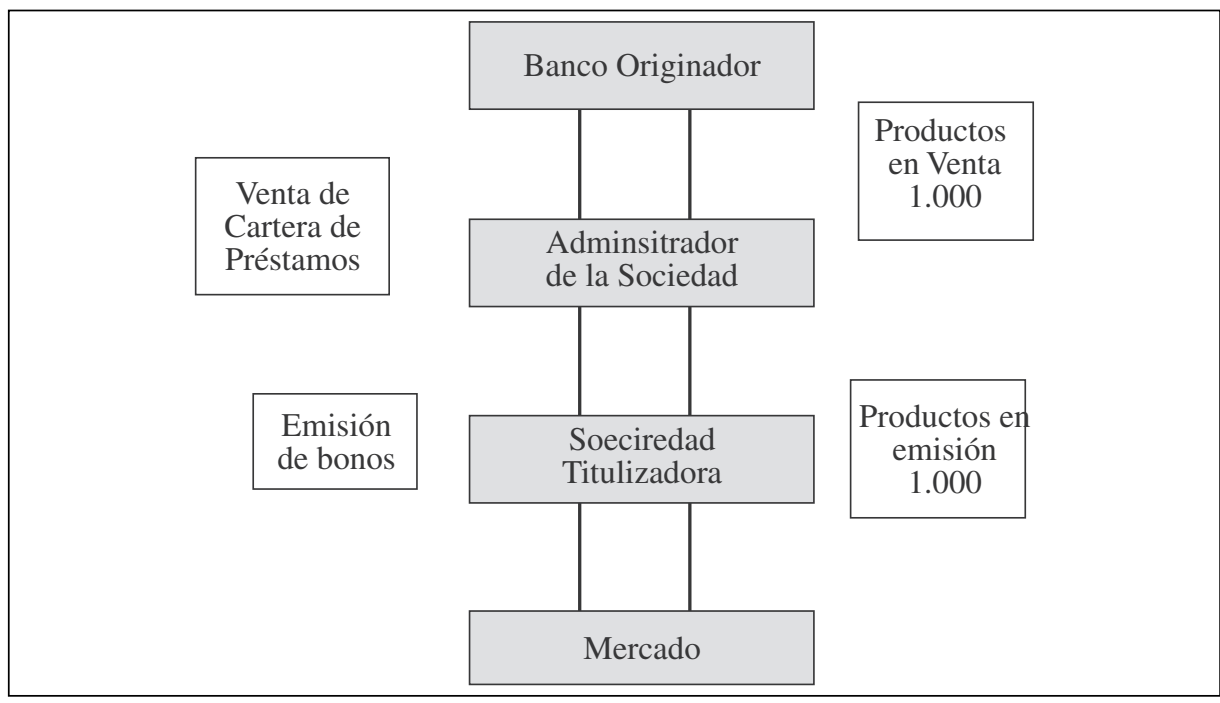

Fuente: Gestión de carteras de renta fija. E. Martínez- Abascal y J. Guasch. McGraw-Hill Professional, 2002.

Los activos susceptibles de titulización son préstamos hipotecarios, los préstamos para adquisición de vehículos créditos comerciales, operaciones de leasing de equipos y las cuentas de tarjetas de crédito. Las operaciones las desarrollan u originan entidades financieras, fundamentalmente bancos de inversión y sociedades vinculadas a grandes corporaciones, que por su actividad generan operaciones que conllevan derechos de cobro susceptibles de ser titulizados. Los títulos o notas emitidas por la sociedad titulizadora se clasifican en tramos o tranches, para atraer a distintos perfiles de inversores. Cada tramo tiene una calificación o rating. Estos tramos suelen ser, senior, junior o mezzanine y equity. El tramo senior tiene una calificación de AAA a A, el junio de BBB a B y el equity no tiene calificación y es el más arriesgado. Cada tramo absorbe las pérdidas producidas en la cartera de referencia hasta su nivel de subordinación. Las primeras pérdidas las absorbe el tramo equity y así, hasta llegar al senior. La figura 2 muestra el esquema de una titulización. 
Figura 2. Titulización

\begin{tabular}{|c|c|c|c|c|c|}
\hline $\begin{array}{l}\text { Tramo } \\
\text { Tramo } \\
\text { Senior }\end{array}$ \\
\hline Senior & 900 & $10,0 \%$ & Pamaño & Subordinación & Rating \\
\hline Tramo A \\
\hline $\begin{array}{c}\text { Tramo B } \\
\text { Equity }\end{array}$
\end{tabular}

Fuente: Manual de instrumentos de renta fija estructurados de tipos de interés y crédito. R. Knop, M. de Castro y J.M. Fernández. Ariel Economía, 2006.

La titulización es ventajosa para el emisor (gestión de balance) y para el inversor (rentabilidad). Destacamos las siguientes ventajas, entre otras:

- La titulización constituye una fuente de financiación, en la medida en que la entidad está vendiendo activos.

- La titulización aporta flexibilidad a la gestión del balance, ya que la entidad vende derechos a cobrar lo que supone la eliminación de activos que requieren recursos propios. El empleo de un volumen de recursos propios menor, aumenta automáticamente la rentabilidad sobre recursos propios por el efecto del apalancamiento. Hay que tener en cuenta que la venta de activos disminuye la base de activos con riesgo ${ }^{1}$ que computa en el ratio de capital que determina el Banco Internacional de Pagos (BIS). Esta ventaja es determinante a la hora de explicar el extraordinario aumento del volumen de deuda en términos relativos a los recursos propios en las entidades financieras a lo largo de los últimos años. Como el apalancamiento tiene efectos simétricos contractivos y

$1 \mathrm{Si}$ en un principio es la entidad la que tiene el derecho a cobrar, al ceder ese derecho también cede el riesgo del activo. 
expansivos sobre los resultados, está siendo también un factor determinante en la menor velocidad de ajuste de los balances de las entidades desde que se inició el proceso de desapalancamiento desde mediados de 2007.

- La titulización es fuente de resultados. Otra ventaja es que el banco, como intermediario que es, cobra un diferencial sobre las hipotecas que tituliza (ya de por si, producto con margen para el banco).

- Desde la perspectiva del comprador de los títulos, la ventaja proviene de la obtención de una rentabilidad superior a la que se obtendría con bonos con un riesgo similar.

Todas estas ventajas ayudan a comprender el interés de las entidades financieras por aumentar este segmento del mercado de deuda.

Figura 3. Financiación estructurada: instrumentos

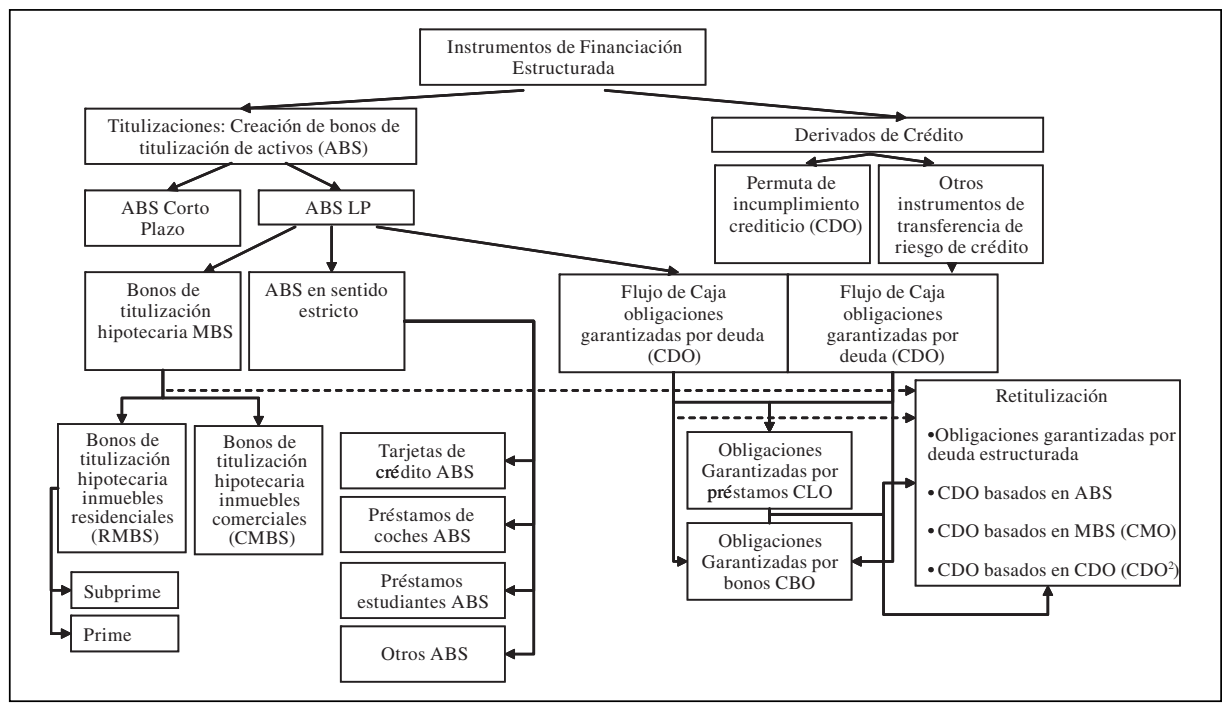

Fuente: La financiación estructurada y las turbulencias financieras de 2007-2008. Introducción general. Banco de España, 2008.

La titulización de activos y los instrumentos derivados de crédito en conjunto es lo que se denomina la financiación estructurada. En el siguiente diagrama vemos ejemplos de los dos instrumentos de financiación estructurada a los que hacemos referencia. 
No obstante, hubo otra serie de elementos que condicionaron el proceso de apalancamiento, como fue el desarrollo de una infraestructura para el funcionamiento de los instrumentos derivados de crédito, lo que en su conjunto se ha llamado el shadow banking system ${ }^{2}$.

Sin este sistema no habría sido posible el crecimiento del excesivo y oculto apalancamiento, clave en esta crisis.

Figura 4. El «shadow banking system»

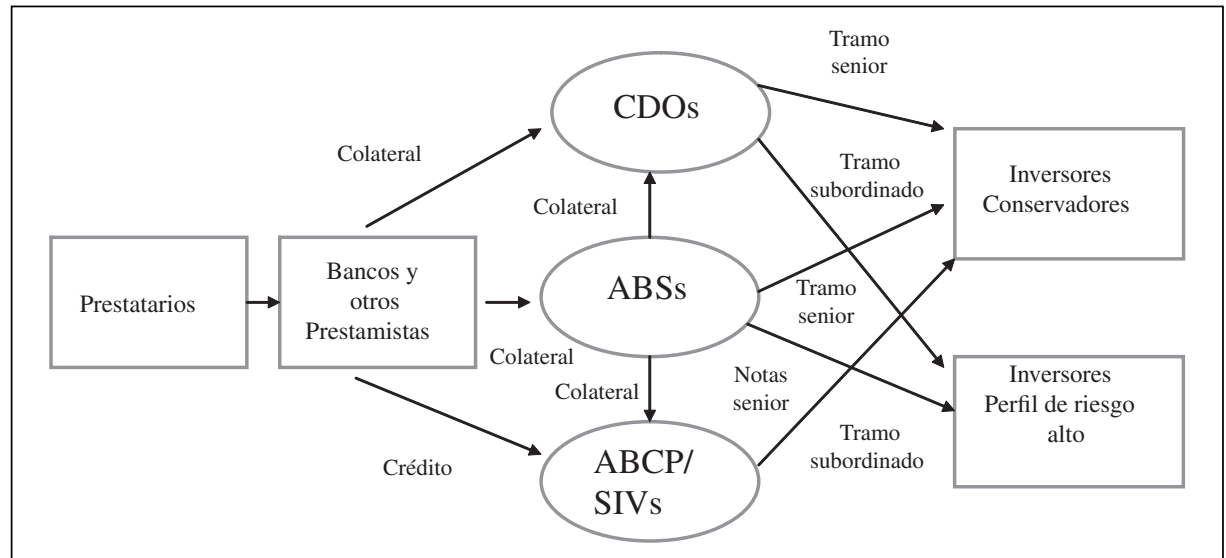

Fuente: «Policy lessons from the recent financial market turmoil» Hervé hannoun, BIS mayo 2008.

La estructura financiera tradicional se ajustó para poder aumentar márgenes como modelo de negocio, tratando de suplir el menor rendimiento de las operaciones que tradicionalmente se habían realizado en los mercados de deuda. El negocio de la estructuración cada vez se veía como una fuente de resultados en si misma. Las entidades favorecían la concesión de préstamos para poder después titulizarlos o realizar derivados sobre ellos; las implicaciones no sólo se apreciaban en los mercados financieros, sino también en la economía real.

Los condicionantes económicos y financieros que hemos descrito anteriormente, relajación monetaria y desarrollo de instrumentos financieros que favorecían el endeudamiento, llevaron a un excesivo apalancamiento de las economías, tanto por el lado de

2 Que traducido sería «sistema bancario en la sombra», porque está constituido por sociedades instrumentales cuyas operaciones no aparecen en los balances de los bancos. 
los bancos, de las empresas no financieras, como de las familias. En este contexto, el crecimiento de la economía mundial se situó por encima del crecimiento potencial, lo que llevó a partir de 2004 a implementar políticas monetarias menos laxas, incrementando los tipos a los distintos bancos centrales, si bien el papel de la Reserva Federal fue clave, por la importancia de la economía americana para el resto del mundo y por estar radicados en EEUU los mayores bancos de inversión del mundo.

En este contexto, como argumenta el BIS en una de sus conferencias del pasado año $(\mathrm{H}$. Hannoun, Mayo 2008), se esperaba una corrección de la sobrevaloración de los mercados de crédito después de la fuerte expansión de los últimos años, pero no se esperaba que tuviera las consecuencias en los ámbitos financiero y de la economía real que se alcanzaron.

\subsection{La subida de los tipos de interés como catalizador de la crisis}

La subida de los tipos de interés por parte de la Reserva Federal a partir del segundo semestre de 2004 no tuvo un efecto inmediato. Se partía de unos niveles de tipos de interés bajos, lo que permitía soportar bien el incremento del servicio de la deuda. Los bancos seguían desarrollando su actividad de estructuración con préstamos cada vez de peor calidad. En 2006 se impulso la creación de índices que reflejaban el mercado de hipotecas de alto riesgo $(\mathrm{ABX})$, lo que constituía un claro exponente de la relevancia que estaba tomando este segmento del mercado de crédito. La Reserva Federal subió los tipos de interés hasta el $5.25 \%$ desde el $1.00 \%$ con el que se había comenzado el proceso de restricción monetaria.

Figura 5. Tipo repo de la Reserva Federal, y PIB EEUU

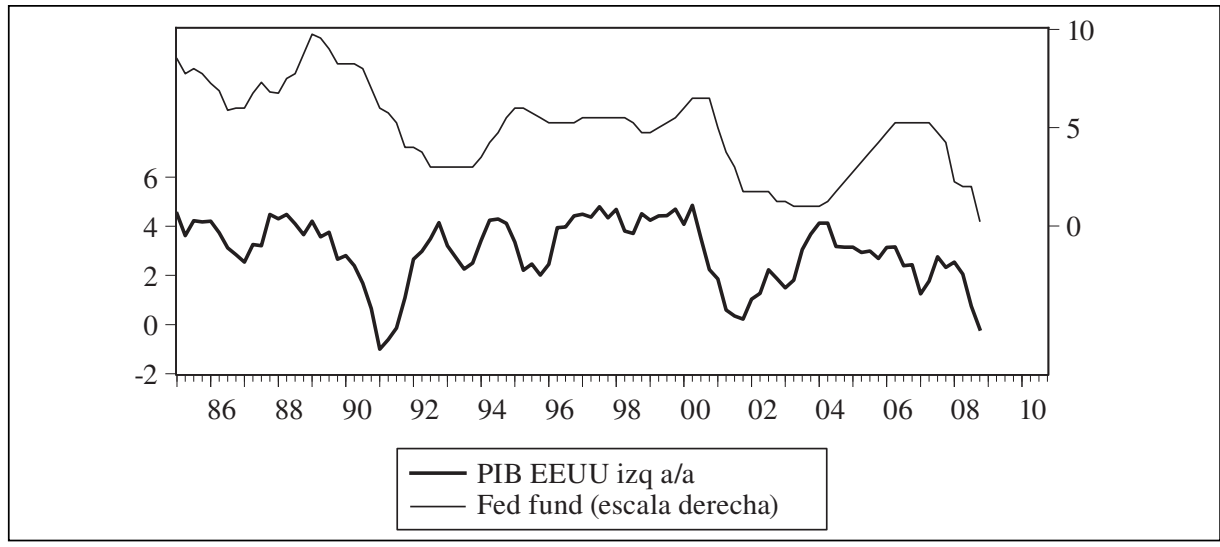

Fuente: Elaboración propia en base a datos de Bureau of Labor Statistics EEUU. 
El endurecimiento de las condiciones monetarias redujo la demanda de bienes sensibles a tipos de interés. Los tipos de interés comenzaron a subir en junio de 2004 (fig.5) y el mayor impacto acumulado de las subidas se aprecia con una carencia de 12 a 18 meses, lo que supuso que los efectos empezaran a observarse con claridad en 2006.

La subida de tipos supuso, por un lado, la disminución de la actividad y por lo tanto una menor creación de empleo, cuando no destrucción, que era más evidente en los puestos más precarios. Por otro lado, la actividad de la construcción y del sector inmobiliario disminuyó. Este descenso supuso que los precios de las casas se estancaran o comenzaran a caer, lo que frenó drásticamente la dinámica que se había impuesto en los últimos años, en la que el banco concedía un préstamo a una persona con perfil de alto riesgo y con período de carencia en los pagos. Llegado el momento de comenzar a pagar, el prestatario renegociaba la hipoteca aprovechando que el precio de la casa había subido, lo que le permitía hacer frente a los pagos. Esta práctica no sólo estaba indicada para los perfiles de riesgo más arriesgados, sino también los que tenían mayor capacidad de pago (Prime), lo que favoreció durante la expansión una subida de precios mayor. Pero el punto más débil eran las hipotecas de alto riesgo (subprime), ya que en el momento en el que subieron los tipos, las casas no vieron aumentado su precio como había sido en momentos en los que las condiciones monetarias eran relajadas y adicionalmente, los tipos habían subido, de manera que los costes de financiación se hicieron inasumibles.

Figura 6. Morosidad hipotecaria (\%)

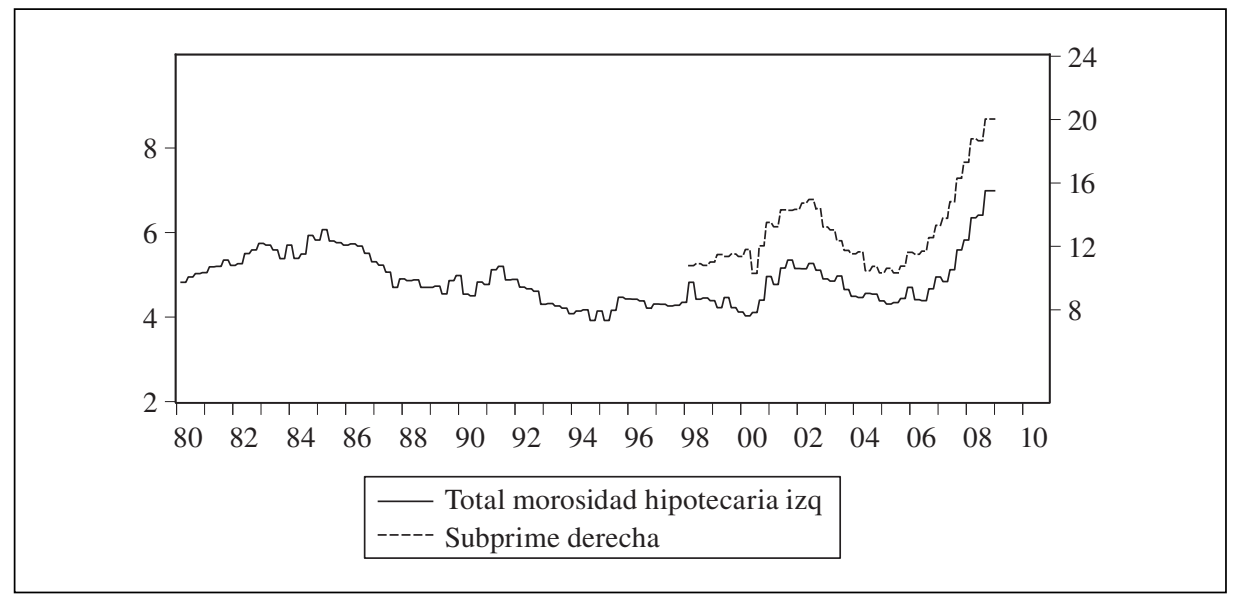

Fuente: Elaboración propia en base a datos de Bloomberg. 
Los impagos comenzaron a subir de forma acelerada desde la segunda mitad de 2006 y puso en evidencia todas las debilidades del sistema financiero y de crecimiento que imperaba. La celeridad con la que se han ido produciendo los acontecimientos pone de manifiesto la interrelación de las actividades en los mercados financieros, la fragilidad de las bases sobre las que se asentaban los modelos de negocio en los mismos y la excesiva dependencia de la economía real del endeudamiento, en lugar de una posición más equilibrada entre recursos propios y ajenos.

Para tratar de explicar de forma más detallada porque los mercados financieros colapsaron, es profundizar ligeramente en el funcionamiento de la financiación estructurada, en concreto hemos tomado como referencia un ejemplo de retitulización como es un CDO (Collateralized Debt Obligations) de ABS (Asset Backed Security). Un CDO son obligaciones de deuda colaterizada. Básicamente, estos vehículos financieros se estructuran con parte de un ABS de una calidad crediticia o rating AAA y el resto inferior. Así, como se aprecia en la fig. 7, la cartera de un CDO se componía de titulizaciones (ABSs) que a su vez se habían estructurado con una cartera de préstamos de distinta calidad, de ahí que podamos decir que es una retitulización o titulización de una titulización. Al igual que en el caso de una titulización de ABS, se estructura en tramos, cuyo riesgo y, por lo tanto su rating, depende del grado de subordinación. El extremo más arriesgado es el tramo (tranch) equity, constituido por deuda de muy baja calidad (subprime). Habitualmente, este tramo era asegurado por empresas que se dedicaban específicamente a ese negocio, las monolines, con el objeto de poder salir al mercado en condiciones más ventajosas. El proceso de estructuración llevaba a componer una cartera con distintas calidades crediticias que, por la diversificación que suponía, reducía el riesgo de la cartera en conjunto, lo que suponía una mejora en calidad crediticia. Se daba la paradoja que carteras con un rating promedio bajo, por la diversificación convertía a la cartera en su conjunto en un rating más alto.

Las personas que hayan estudiado los conceptos básicos de la teoría de la diversificación advertirán que esta solución es posible. Una cartera suficientemente diversificada puede dar más retorno con el mismo nivel de riesgo o el mismo retorno con menos riesgo. No obstante, para que esto se pueda dar, se tienen que cumplir las premisas de partida, los inputs que sirven para evaluar el riesgo. Bien porque no se evaluó el riesgo o bien porque los inputs de partida no fueron los adecuados, básicamente en lo referente a las distribuciones conjuntas de la cartera, se estaba infraestimando el riesgo que suponía la posesión de este tipo de instrumentos en cartera. Por esta razón en el momento que se empezaron a subir los tipos de interés, los impagos de las hipotecas empezaron a impactar en este tipo de productos de manera más acusada de lo estimado. El riesgo de una correlación entre los activos que componían la cartera era mucho mayor (ausencia 
de diversificación en entorno de crisis), lo que llevó a provocar caídas en los precios de las titulizaciones de manera acusada en un corto espacio de tiempo.

Figura 7. Estructuración de CDO y la figura de las «monolines»



Fuente: Elaboración propia.

Así pues, la subida de los tipos de interés tuvo efecto en el eslabón más frágil de la cadena: las hipotecas subprime. Además afectó rápidamente al resto del sistema que se encontraba apalancado en exceso, aprovechando la facilidad con la que se concedían los créditos, el bajo coste de los mismos. Haciendo una breve descripción de los acontecimientos, el aumento de la morosidad en las hipotecas subprime puso de manifiesto el verdadero riesgo de las estructuras como los CDOs. Esto puso en duda las calificaciones de las agencias de rating, fundamentales para dar credibilidad al sistema, reduciéndose la liquidez en los mercados al subir el riesgo de contrapartida. Las dificultades de estructuras como los CDOs se transmiten a este mercado de financiación apalancada. Los bancos comienzan a quedarse con las deudas en balance ante la imposibilidad de titulizar. Las sociedades titulizadoras comienzan a tener problemas para financiarse a corto plazo (que era la forma más habitual de hacerlo). Los asset backed commercial paper $(A B C P)$ dejan de ser fuente de financiación, lo que lleva a la liquidación de numerosas sociedades instrumentales titulizadoras (SIVs, Conduits) que forman parte del shadow banking system que veíamos anteriormente. Las revisiones de rating de las emisiones ponen en dificultades a las aseguradoras de emisiones, las monolines, que se quedan al borde de la desaparición.

Las dificultades anteriormente descritas, a saber, la falta de liquidez de las sociedades titulizadoras, la incertidumbre sobre la valoración de los activos vinculados a 
los productos estructurados y la necesidad de mantener en balance las deudas, afecta muy negativamente a los bancos y a la confianza entre ellos, por las pérdidas potenciales que puedan tener. El shadow system permitía cierto grado de opacidad en el apalancamiento.

Esta pérdida de confianza favoreció un extraordinario tensionamiento en los tipos del mercado interbancario.

Figura 8. Tensionamiento de tipos de interés: Fed Fund y Euro depósito

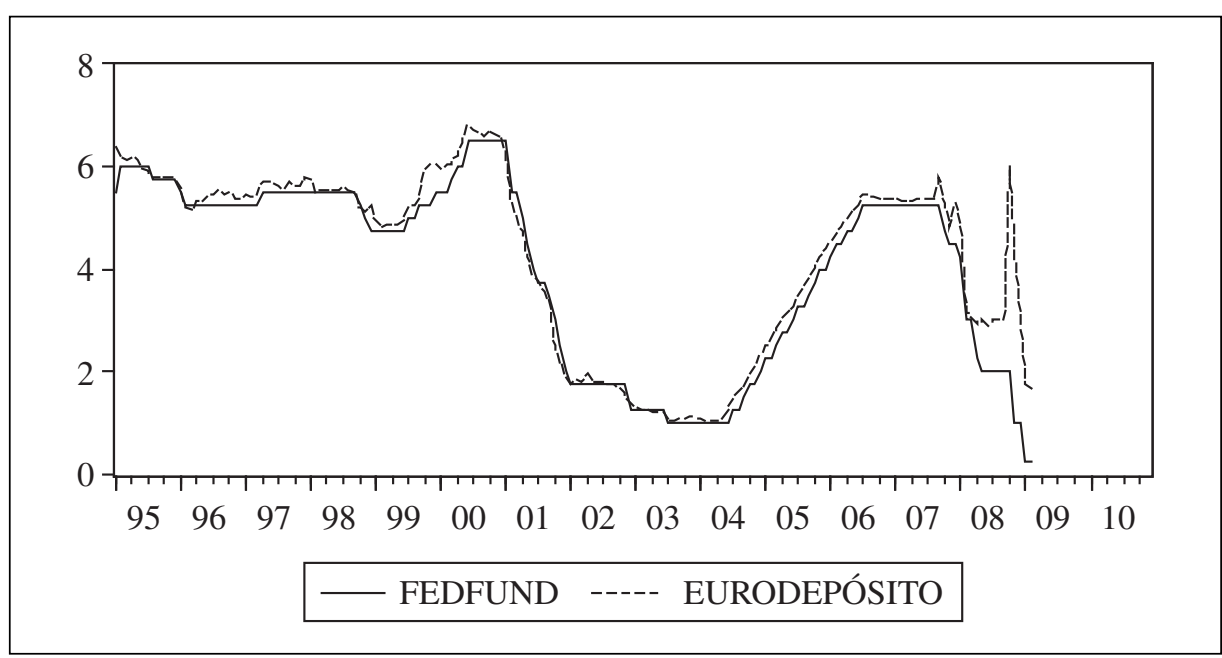

Nota: Tipo de cambio de la Reserva federal y Euro depósito, equivalente del Euriobor para bancos sin ficha bancaria en la Euro zona.

Fuente: Bloomberg.

Este mercado, en el que se prestan los bancos entre sí, ve reducida la liquidez por la falta de intercambios entre entidades financieras por la desconfianza. Los bancos se encuentran con una cartera de activos, que en muchas ocasiones no pueden valorar porque no hay mercado, otros se sabe que valen mucho menos de lo que estaba contabilizado y, por el lado del pasivo, la deuda es creciente y como suele ser habitual, la financiación en una proporción importante es a corto plazo. La desconfianza en otras entidades y las potenciales dificultades de financiación, cuando no reales, llevan a las financieras a preservar la liquidez, lo que con el tiempo afecta a la economía real. La crisis de liquidez derivará en una crisis de solvencia adicional, agravando la crisis financiera. 
Figura 9. Fases en la crisis hipotecaria 2007-2008

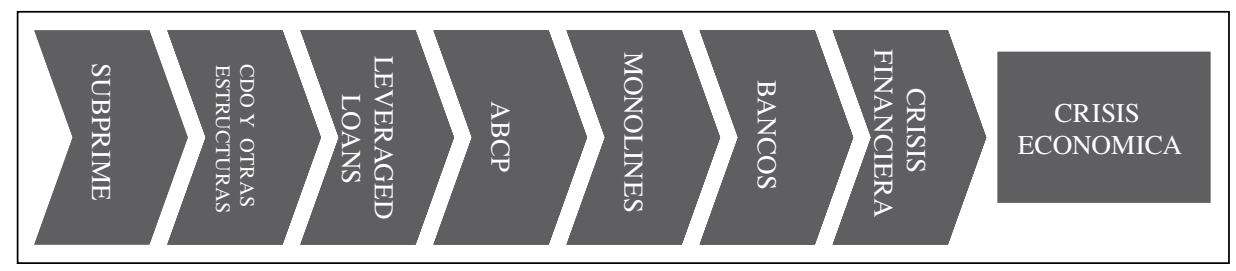

Fuente: Elaboración propia.

\section{Situación ACTUAL}

La pérdida de confianza generalizada en los mercados interbancarios y de crédito, ha llevado a una crisis de liquidez y solvencia, en un contexto de endeudamiento de empresas y familias por encima de los estándares históricos, lo que ha provocado la necesidad de un desapalancamiento significativo de las economías, en particular de las desarrolladas.

Si bien es cierto que los efectos más llamativos de la crisis los estamos observando en las entidades financieras, su situación es reflejo de lo que ocurre en el resto de la economía. Tomaremos como ejemplo del grado de apalancamiento de las entidades financieras de acuerdo con el último informe de estabilidad financiera de octubre de 2008 del Banco de Inglaterra. Citaremos también algunos datos de la economía real para observar que el exceso de endeudamiento no es un fenómeno exclusivo de las entidades financieras. Para ello, nos valdremos de las estadísticas de la economía de los EEUU, por tener bases de datos más amplias con las que poder comparar en el tiempo, y por la influencia de esta en el resto de economías del mundo.

De acuerdo con el informe de estabilidad financiera del Banco de Inglaterra de octubre de 2008, los bancos tenían un ratio de apalancamiento ${ }^{3}$ superior al que registraban en verano de 2007, fecha en la que se puede marcar el comienzo de las turbulencias financieras. Es más, el ratio no ha dejado de crecer entre las dos fechas. La dinámica observada en los bancos ingleses puede extrapolarse, con matices, al resto de áreas de-

3 El ratio de apalancamiento definido como activos totales divididos por los recursos propios excluyendo intereses de los minoritarios. Para más información ver Financial Stability Report Bank of England oct 2008. 
sarrolladas. El nivel de apalancamiento puede ser mayor en los bancos ingleses, pero la evolución de los mismos en los bancos de las áreas desarrolladas es parecida.

Figura 10. Apalancamiento bancario

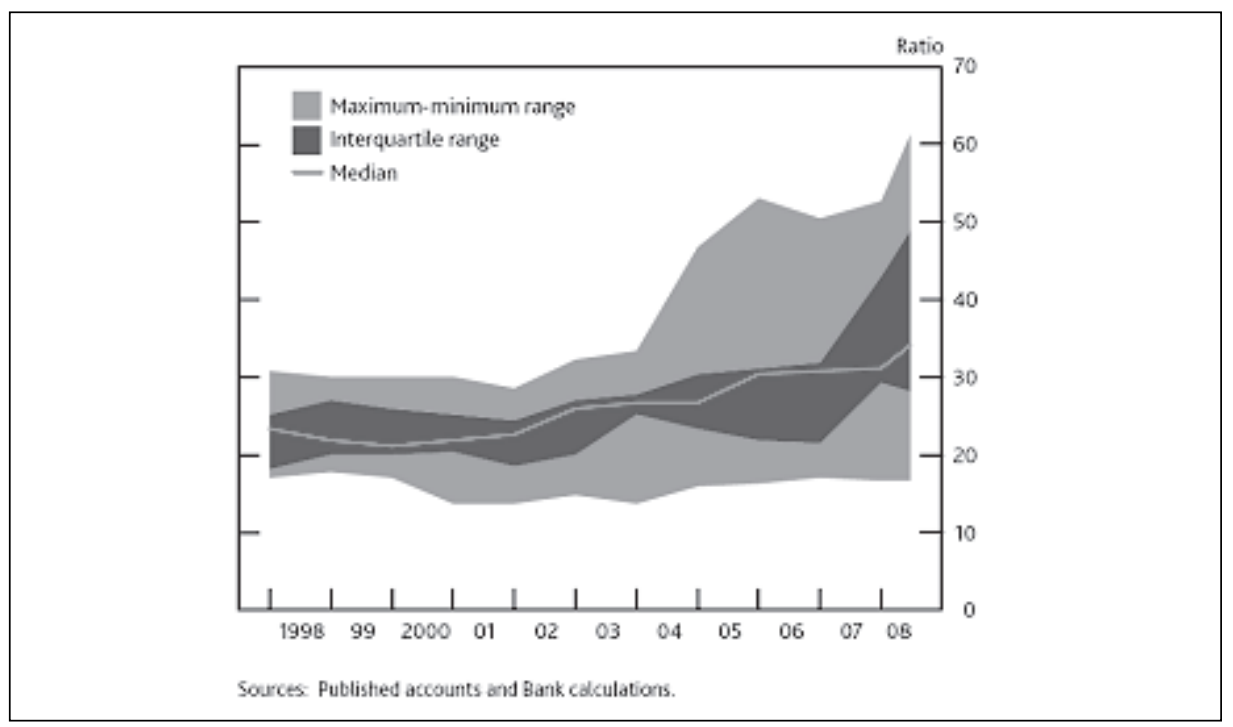

Fuente: Banco de Inglaterra.

Como comentábamos antes, el apalancamiento no es un fenómeno exclusivo de las entidades financieras. En el caso de las empresas no financieras, el grado de apalancamiento también ha sido significativo. Con datos del tercer trimestre del año 2008, las necesidades de financiación de las empresas no financieras en EEUU (financing gap), en términos relativos a su PIB, era de aproximadamente el 1.9\%. Aunque el descenso respecto al segundo trimestre ha sido apreciable, en el que el registro fue del $3.9 \%$ y fue el dato mayor de este ciclo, la apelación a los recursos ajenos sigue elevada, como se puede apreciar en la fig. 9 . Los niveles no son tan elevados como los alcanzados en el año 2000 o en las crisis del 74 o el 80, pero sí lo son teniendo en cuanta que llevamos un año y medio de crisis.

El apalancamiento es más llamativo en el caso de las familias. Tomando como referencia la contabilidad nacional de los EEUU (NIPA), si observamos el ratio entre deudas y el total de los activos, vemos que a cierre del tercer trimestre del año, el ratio se encontraba en máximos de las últimas décadas y mostraba una aceleración en los últimos trimestres. Esto sucedía a pesar de que los hogares estadounidenses comenzaron a recortar su ritmo de endeudamiento. 
Figura 11. Necesidades de financiación de la empresa no financiera

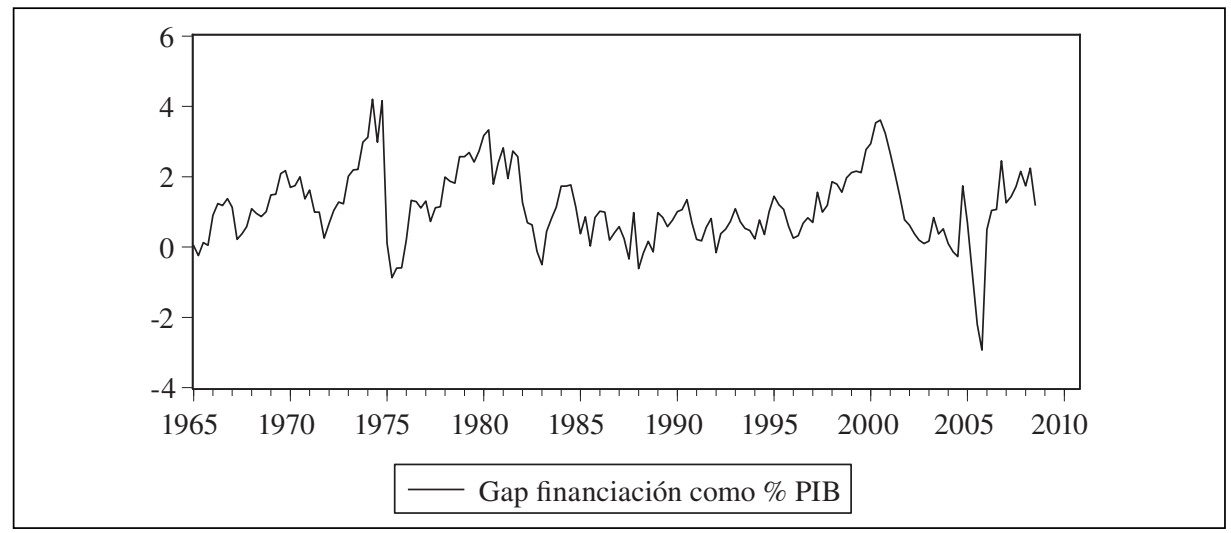

Fuente: Flow of Funds de la Reserva Federal EEUU.

El total de la economía se mantiene significativamente apalancada, a pesar de haberse restringido el crédito sustancialmente en los últimos trimestres y los esfuerzos por entidades financieras y empresas no financieras por ajustar los balances. También se aprecia un una reducción significativa del consumo de las familias, sin que se aprecie un cambio en las tendencias en su nivel de apalancamiento. Ante la evolución observada cabría preguntarse si ha sido insuficiente la reacción de empresas y familias y dónde nos encontramos en el proceso de desapalancamiento en cada una de las unidades de la economía.

Figura 12. Endeudamiento de las familias en Estados Unidos

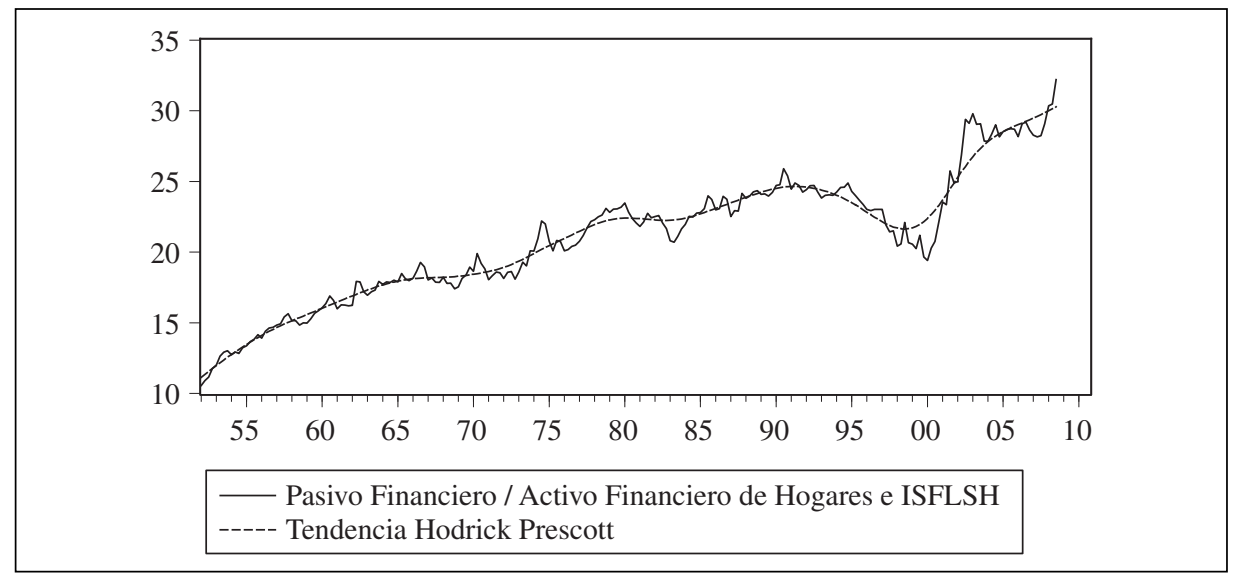

Fuente: Flow of Funds de la Reserva Federal EEUU. 
Respondiendo a estos interrogantes, podría decirse que ha habido una reacción desigual, lo que ha determinado la fase en la que se encuentran unidades financieras, no financieras y familias. Antes de evaluar el momento actual en el que podrían encontrarse cada una de las unidades anteriormente mencionadas, conviene apuntar las formas de desapalancar una unidad económica.

El desapalancamiento es un proceso lento, ya que la forma de impulsarlo puede tener un efecto adverso al inicio, produciendo un mayor apalancamiento inicial. Hay diversos métodos de desapalancamiento, entre los que convendría destacar: Venta de activos y pago de las deudas pendientes. Supone una reducción del tamaño del balance.

- Ampliación de capital, lo que provoca un efecto directo de reducción del ratio de activos totales sobre recursos propios.

- Reducción del dividendo para incrementar los recursos propios (autofinanciación).

Las entidades financieras han realizado una parte importante del camino. Las que se encontraban excesivamente apalancadas y han tenido problemas de liquidez o han quebrado, han sido adquiridas por otras entidades financieras o han recibido financiación del estado, recapitalizándolas. La necesidad de normalizar el funcionamiento por el lado de la oferta del mercado de crédito ha llevado a las autoridades monetarias a forzar un proceso de desapalancamiento acelerado, propiciando un ajuste mayor de lo que las fuerzas del mercado habrían determinado. El problema adicional con el que se van a encontrar las entidades financieras, es el efecto negativo provocado por la desaceleración económica, en un contexto en el que la prioridad debería ser la ampliación de márgenes, que sustituya el objetivo de volumen que ha prevalecido en los últimos años.

Dentro del sector financiero la evolución del desapalancamiento es desigual.

Aunque los bancos mantienen un ritmo acelerado en la reducción de financiación ajena, existen el riesgo y necesidad de desapalancarse en aquéllas empresas que, de acuerdo con la normativa que les rige, no han tenido obligación de reconocer la pérdida de valor día a día (mark to market). Sería el caso, por ejemplo, de las entidades aseguradoras. La falta de reconocimiento de la pérdida de valor de los activos limita la necesidad de desapalancarse y provisionar, pero también condiciona la actividad futura de la empresa. Una vez más, de acuerdo con el informe de estabilidad financiera del Banco de Inglaterra, las aseguradoras mantenían antes de la crisis posiciones importantes en productos del mercado de mercado de crédito que ha registrado importantes pérdidas (CLOs o CDOs), llegando prácticamente a su desaparición en alguno de ellos, sin que se haya visto reconocida la pérdida en las cuentas de las compañías aseguradoras en la misma proporción. 
Fig 13. Financiación estructurada en manos de instituciones financieras del Reino Unido

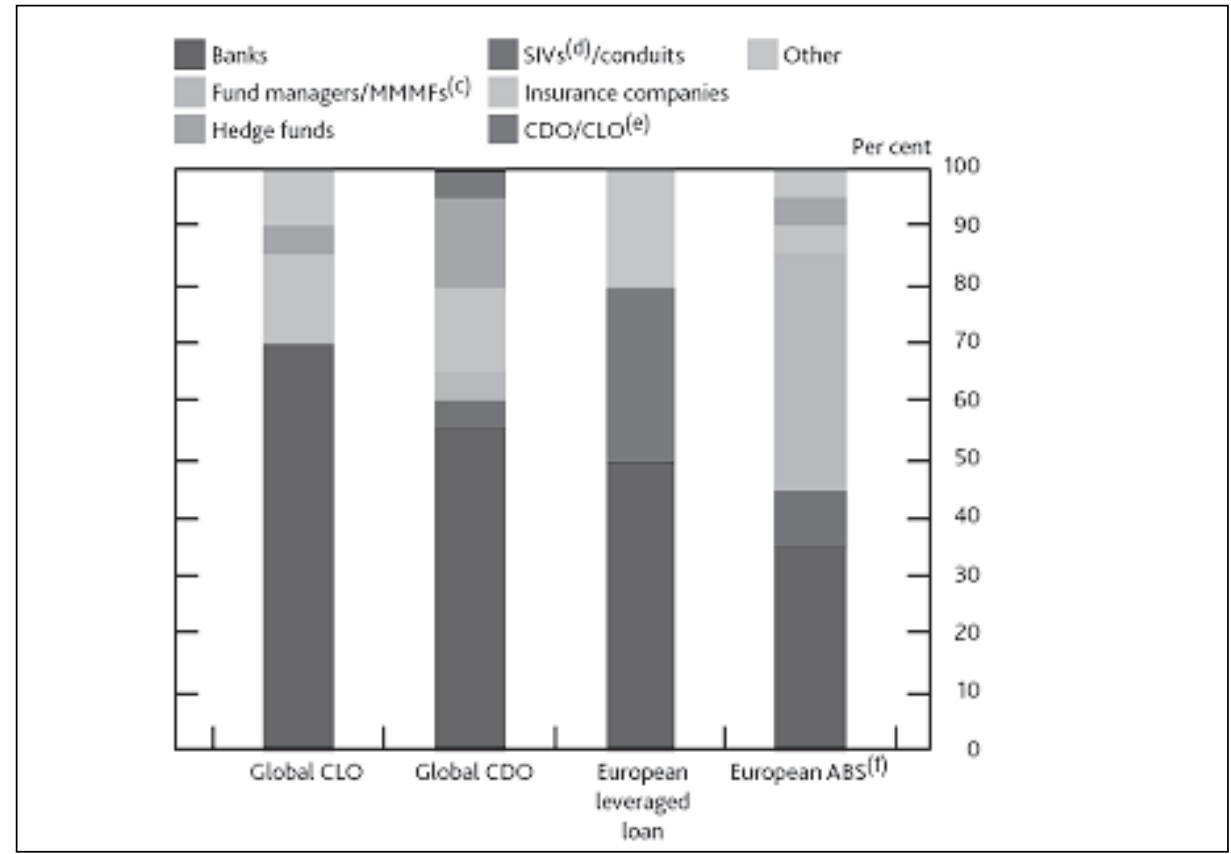

Fuente: Banco de Inglaterra citando a Citi, JPMorgan Chase \& Co. Lehman BROS. S\&P.

Las necesidades de financiación de las empresas, de las que hemos hablado anteriormente para el caso de las compañías de los EEUU, ponen de manifiesto que una gran parte del ajuste todavía no se habría realizado. La necesidad de financiación externa es incluso más elevada en el caso de las empresas europeas.

En el caso de las familias, el proceso de desapalancamiento estaría comenzando a producirse. La situación de las familias es relevante, porque condicionará el ritmo de normalización del mercado de crédito por el lado de la demanda. Posteriormente abundaremos algo más en este punto, cuando hablemos de las medidas adoptadas y la evolución prevista para la economía y los mercados.

Atendiendo a la evolución de la crisis desde la perspectiva de los activos que se encuentran principalmente involucrados, los resultados apuntan en el mismo sentido; ha habido desapalancamiento, pero la potencial necesidad de desapalancarse adicionalmente por la pérdida de valor de los activos es grande. Observando la evolución de las pérdidas que se han producido en los mercados de renta fija no tesoros en Reino 
Unido, EEUU y Zona Euro, en términos medios, las pérdidas son relativamente bajas en porcentaje sobre el total de deuda en mercado. Destaca el reducido porcentaje de pérdidas declaradas en CDOs o en CLOs, teniendo en cuenta la evolución que ha tenido el mercado de estos activos.

Figura 14. Pérdidas por instrumento renta fija y país

\begin{tabular}{|c|c|c|c|c|c|}
\hline & $\begin{array}{l}\text { Cantidades } \\
\text { en Mercado }\end{array}$ & $\begin{array}{c}\text { Pérdidas } \\
\text { Abril } 2008\end{array}$ & $\begin{array}{c}\text { Pérdidas } \\
\text { Octubre } \\
2008\end{array}$ & $\begin{array}{c}\text { Pérdidas } \\
\text { Abril } 2008 \\
\% \text { Debt } \\
\text { Outstanding }\end{array}$ & $\begin{array}{c}\text { Pérdidas } \\
\text { Octubre } \\
\text { 2008 \% Debt } \\
\text { Outstanding }\end{array}$ \\
\hline \multicolumn{6}{|l|}{ Reino Unido (miles millones libras) } \\
\hline Prime RMBS & 193 & 8.2 & 17.4 & $4 \%$ & $9 \%$ \\
\hline Non Comfirming Residential MBS & 39 & 2.2 & 7.7 & $6 \%$ & $20 \%$ \\
\hline Commercial MBS & 33 & 3.1 & 4.4 & $9 \%$ & $13 \%$ \\
\hline Investment Grade Corp. Bonds & 450 & 46.2 & 86.5 & $10 \%$ & $19 \%$ \\
\hline High Yield Corp. Bonds & 15 & 3 & 6.6 & $20 \%$ & $44 \%$ \\
\hline Total & & 62.7 & 122.6 & & \\
\hline \multicolumn{6}{|l|}{ EEUU (miles de millones dólares) } \\
\hline Home Equity Loan ABS & 757 & 255 & 309.9 & $34 \%$ & $41 \%$ \\
\hline Home Equity Loan ABS Collateralised Debt Obligations (CDO & 421 & 236 & 277 & $56 \%$ & $66 \%$ \\
\hline Commercial MBS & 700 & 79.8 & 97.2 & $11 \%$ & $14 \%$ \\
\hline Collateralised Loan Obligations & 340 & 12.2 & 46.2 & $4 \%$ & $14 \%$ \\
\hline Investment Grade Corp. Bonds & 3308 & 79.7 & 600.1 & $2 \%$ & $18 \%$ \\
\hline High Yield Corp Bonds & 692 & 76 & 246.8 & $11 \%$ & $36 \%$ \\
\hline Total & & 738.7 & 1577.2 & & \\
\hline \multicolumn{6}{|l|}{ Euro Area (Miles Millones euros) } \\
\hline RMBS & 387 & 21.5 & 38.9 & $6 \%$ & $10 \%$ \\
\hline Commercial MBS & 34 & 2.8 & 4.1 & $8 \%$ & $12 \%$ \\
\hline Collateralised Loan Obligations & 103 & 6.8 & 22.8 & $7 \%$ & $22 \%$ \\
\hline Investment Grade Corp. Bonds & 5324 & 283.8 & 642.9 & $5 \%$ & $12 \%$ \\
\hline High Yield Corp. Bonds & 175 & 29.1 & 75.9 & $17 \%$ & $43 \%$ \\
\hline Total & & 344 & 784.6 & & \\
\hline
\end{tabular}

Fuente: Elaboración propia con base de datos Banco de Inglaterra.

En la tabla siguiente (fig. 14) se ofrece detalladamente la evolución de los distintos activos de renta fija, en la que se comparan las pérdidas a abril de 2008 y a octubre de 2008. Se han incrementado notoriamente las pérdidas prácticamente en todos los segmentos, pero el potencial de pérdidas es todavía elevado. 


\subsection{Medidas practicadas hasta el momento}

Las medidas de contención de la crisis básicamente serían:

- Políticas monetarias expansivas, tanto ortodoxas como heterodoxas.

- Garantía sobre los depósitos para evitar la corrida de depósitos ${ }^{4}$.

- Recapitalización de entidades financieras, llegando incluso la nacionalización.

- Políticas fiscales expansivas.

Todas estas medidas van encaminadas a recapitalizar las entidades financieras y a la generación de confianza en el sistema, con el objeto de que se normalicen los mercados financieros, en términos de liquidez como de solvencia. Se trata de acometer planes de ayuda que normalicen al mercado por el lado de la oferta. Siendo estas medidas necesarias, conforme ha ido evolucionando la crisis ha quedado patente la necesidad de realizar otras complementarias a las ya citadas que impulsen la demanda. Como ya se ha comentado anteriormente, el proceso de desapalancamiento prácticamente acaba de comenzar en el sector familias. Las caídas del valor de los activos en posesión de las familias y los bajos niveles de ahorro han compensado la reducción de la apelación a la deuda, lo que ha llevado a los ratios de apalancamiento de las familias a niveles superiores incluso a la crisis. El servicio de la deuda sigue próximo a máximos por lo que es necesaria una reducción del mismo, o bien de la deuda total. Desde el punto de vista macroeconómico, es necesaria una recomposición de los saldos de familias, empresas, gobierno y sector exterior, que los lleven a niveles sostenibles de medio plazo. Atendiendo a la igualdad macroeconómica (fig.13): era tradicional que el superávit de las familias financiara a empresas y al sector público.

\section{Figura 15. Identidad macroeconómica de financiación}

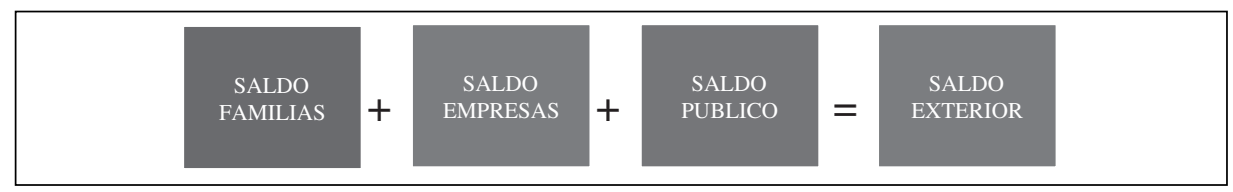

Fuente: Elaboración propia.

4 Se denomina corrida de depósitos a la salida masiva de depósitos en un corto período de tiempo por alguna medida, interna de la empresa o por riesgo sistémico, que provoca la desconfianza en la entidad. 
En los últimos años, la facilidad de acceso al crédito y la disciplina fiscal por parte de las haciendas públicas, así como la mejor gestión de las empresas y la reducción de impuestos para favorecer la inversión, ha supuesto una acumulación de déficit por parte de las familias que han incrementado su stock de deuda. En el caso de EEUU o España, por citar algunos ejemplos, ha llevado al ratio de deuda en términos de renta bruta disponible a niveles históricamente altos, que hacen muy difícil que las familias reaccionen a la relajación de condiciones monetarias. Como ya se ha observado con el paquete de estímulo fiscal que se puso en práctica en el segundo trimestre de 2008, una parte importante del dinero que se dio a las familias fue a recomposición de ahorro (se estima que aproximadamente el $50 \%$ fue a acumular ahorro pero no hay estadística oficial). También se está viendo este fenómeno en el impacto que están teniendo las medidas de relajación monetaria que ha llevado a cabo la Reserva Federal. De acuerdo con la encuesta que realiza la Reserva Federal sobre los estándares de crédito que se aplican en EEUU del mes de enero de 2009, el porcentaje de bancos que respondieron que habían registrado un incremento de demandas de crédito para el consumo apenas había experimentado cambios desde los mínimos cercanos al - 50\% que había alcanzado en la encuesta practicada en octubre.

De acuerdo con estas estadísticas, las familias están recomponiendo sus propios balances y las medidas que se han adoptado para estabilizar el sistema financiero no han supuesto cambios significativos en la demanda de créditos.

De acuerdo con lo acontecido hasta el momento, son necesarias medidas adicionales que hagan compatibles las finanzas de las familias con una demanda de créditos más elevada. La adopción de las mismas supondrá una recomposición de los saldos anteriormente mencionada.

Figura 16. Bancos que reportan incremento de demanda de crédito consumo



Fuente: Senior Loan Officer Survey, Federal Reserve. 


\section{PeRsPeCtivas}

Hasta ahora hemos hecho un sucinto repaso de las causas y la situación económicofinanciera actual y de las soluciones propuestas. El origen de la crisis lo encontramos en un crecimiento desproporcionado del mercado de crédito apoyado en una política monetaria relajada, el desarrollo de productos con hipótesis sobre su comportamiento futuro poco realistas y una regulación que favorecía un sistema financiero fuera de los balances de las entidades financieras. Las consecuencias en los mercados comenzaron a observarse a partir del tercer trimestre de 2007, pero en la economía no se empezaría a verse impactada con claridad hasta finales del mismo año. El razonamiento que a nuestro juicio debe presidir a la hora de realizar el diagnóstico de la situación económica tiene su base en los efectos que se derivan de un desapalancamiento forzado, que podrían verse matizados por los esfuerzos y medidas monetarias y fiscales que se están practicando. Básicamente, el desapalancamiento origina menor crecimiento y deflación de activos, tanto reales como financieros. El problema se acentúa, en la medida en que prácticamente todas las áreas económicas representativas a nivel mundial se apalancaron en exceso en los últimos años. Los efectos del apalancamiento son simétricos para las economías. Siempre y cuando la rentabilidad de los negocios esté por encima del coste de capital, el apalancamiento será positivo, pero cuando la actividad cae, estar excesivamente apalancado nos aporta pérdidas en la misma proporción que los beneficios obtenidos por este efecto en épocas de expansión. Este efecto provoca la necesidad de rebajar las deudas cuando el ciclo es contractivo. Rebajar nuestro ratio de activos totales sobre recursos propios en muchas ocasiones supone la reducción del balance de una empresa. En el caso de la economía igual; la desaparición de una fuente importante de financiación provoca el cierre de proyectos y la caída en la inversión en otros nuevos. Parece evidente que, mientras se mantenga el proceso de desapalancamiento, la economía registrará tasas negativas de crecimiento. Con posterioridad, la economía crecerá a un ritmo compatible con las fuentes de financiación de que disponga que, en la situación previsible futura, será menor que el de años precedentes. Cabe esperar por tanto crecimientos más bajos en las economías, siendo las caídas de las tasas mayores en las economías en las que se ha dependido más del endeudamiento. Mientras se produzca el ajuste del tamaño de planta a la baja, el exceso de capacidad supondrá caída de precios, por lo que las economías registrarán procesos de reducción de tasas de inflación y, en algunos casos, deflación. Las políticas monetarias se mantendrán relajadas por algún tiempo, tratando de compensar la pérdida de velocidad del dinero que se está produciendo en el sistema. Atendiendo a la situación por la que atraviesan cada una de las áreas más representativas de la economía y su estructura económica de partida, el posible comportamiento futuro de éstas sería: 
- La economía global se enfrenta al período de desaceleración /recesión más importante desde la segunda guerra mundial.

- En EEUU la economía se enfrenta a una recesión severa, tanto en magnitud como en extensión en el tiempo. Al margen de las cifras, lo relevante es que probablemente registre un período prolongado de crecimiento débil con inflación baja, o deflación, por los factores anteriormente apuntados. A la vez la economía tenderá a corregir los desequilibrios exteriores por menor demanda interna. En la Zona Euro el comportamiento será semejante, con crecimientos negativos y tasas de precios compatibles con procesos deflacionistas. Japón registrará una caída en el crecimiento amplificada, por su excesiva dependencia del sector exterior y se producirá una significativa apreciación del Yen. La moneda japonesa ha servido para financiar proyectos de inversión, al tener tipos muy bajos y ser moneda de referencia de las operaciones de carry trade $e^{5}$. Es previsible que Japón vuelva a entrar en un período de deflación prolongado. Las áreas emergentes, para las que las expectativas anteriores a la crisis de crédito parecían apuntar a la posibilidad de una mayor defensividad en esta crisis que en otras anteriores, podría no escaparar a la recesión. Los efectos de una financiación más cara y escasa se harán sentir en el crecimiento. Las inversiones, tanto directas como en cartera, se están reduciendo drásticamente. Dadas las dificultades por las que atraviesan las economías y su todavía excesiva dependencia del ciclo global, es probable que queden muy limitadas en los próximos años. Puede no ser el fin del vendor finance ${ }^{6}$, aunque si que quedará muy limitado.

El comportamiento de los mercados financieros también quedará marcado por la crisis durante un prolongado período de tiempo, en línea con el lento proceso de desapalancamiento que se espera. A los activos negociados se les exigirá más, en función de que se vean más o menos expuestos a tres factores o primas de riesgo:

5 Carry trade: Operaciones en el mercado de tipos de interés que tratan de aprovecharse del incumplimiento de la teoría de la paridad de los tipos de interés abierta.

${ }^{6}$ Expresión anglosajona que define el proceso por el cual se deslocaliza la producción a las áreas emergentes que luego venden sus productos en los países desarrollados y, posteriormente, los saldos exteriores obtenidos son invertidos en financiación de los desequilibrios exteriores de aquéllos. 
- Prima por liquidez, lo que supondrá que se pagará más por las inversiones con capacidad para deshacerlas sin pérdidas.

- Prima por plazo, que se puede apreciar claramente en la positivización de las curvas de rentabilidades descontadas en los bonos del tesoro, aunque implícito esta en todos los activos que se compran y venden en mercados organizados.

- Prima por crédito. Será necesario un largo período de tiempo para poder ver como se desenvuelven las empresas en un escenario de menor apalancamiento del observado en años precedentes, y posteriormente ajustar las primas exigidas.

A grandes rasgos, estos factores de riesgo deberían condicionar las decisiones de inversión, que se harán más conservadoras. Liquidez y crédito afectan muy limitadamente a los bonos del tesoro. Si la inversión se fija en los plazos cortos de la curva, la prima por plazo también se podría eliminar. Por esta razón cabría esperar un comportamiento relativo mejor de los bonos de gobiernos o cuasi-gobiernos de los plazos cortos de las curvas. El entorno deflacionista favorecerá en cualquier caso un comportamiento positivo de la curva de Tesoros. Será preferible centrar las estrategias en los plazos muy cortos o muy largos frente a los tramos centrales de las curvas ${ }^{7}$.

La prima por crédito afectará negativamente a los bonos corporativos, tanto a aquéllos con grado de inversión como a los de grado de especulación. De la gran cantidad de deuda emitida por las empresas financieras y no financieras, una proporción todavía pendiente de determinar, prácticamente no valdrá nada o verá mermado su valor de manera significativa. Los bonos de las áreas emergentes también recogerán una prima de riesgo más alta que la observada en los últimos años, afectados por el deterioro de los fundamentales. Este empeoramiento de las condiciones financieras y de la economía real del mundo emergente procederá fundamentalmente de la reducción de la inversión directa, como por la caída del comercio exterior y de los precios de las materias primas.

Las acciones, como reflejo del valor de las empresas, también estarán presionadas por un período prolongado de tiempo. Los efectos directos que se derivarán por el menor apalancamiento de las empresas, serán una reducción de la rentabilidad sobre recursos propios y por lo tanto, una caída de las tasas de crecimiento de las acciones. Las valoraciones que se puedan hacer de las compañías reflejarán esta situación, viéndose presionadas a la baja. De este planteamiento puede observase que a las tres primas de riesgo que se incorporarán de forma sistemática a todos los activos, el deterioro de los

7 Estrategias «Barbell» 
fundamentales abundará en la misma dirección en el caso de los títulos de renta variable. Desde el punto de vista de tendencias de los mercados, será difícil que los mercados reviertan a una senda alcista durante un largo período de tiempo, en un contexto de crecimiento débil, con ausencia de poder de transmitir subidas a los precios, menor apalancamiento y con primas de riesgo más elevadas.

Los mercados de divisas se desenvolverán en un entorno de volatilidades elevadas. De las tres divisas de referencia a nivel mundial, el Euro tiene una probabilidad alta de ser el más perjudicado. Existen a nuestro juicio varios condicionantes que favorecerán al Dólar frente al Euro. Por un lado, las medidas que se están adoptando en EEUU hacen previsible una salida más rápida de la crisis al otro lado del atlántico. A esto habría que añadir que la depreciación del Dólar frente a la mayoría de las divisas a lo largo de los últimos años y la reducción de la demanda interna en EEUU ha supuesto una significativa corrección de los desequilibrios exteriores. También, los diferenciales de tipos de interés de los que gozaba la divisa europea frente al Dólar se han reducido y es previsible que lo sigan haciendo en los próximos trimestres. Por último, y no por ello menos importante, el Dólar sigue siendo, por encima del resto, divisa de referencia para los negocios a nivel internacional.

Tal vez la divisa que se vea más fortalecida por el efecto del desapalancamiento sea el Yen. Resulta paradójico que la divisa de un país dependiente del sector exterior, con una economía que ha registrado varias recesiones en las últimas dos décadas e inmersa en un proceso de deflación crónica pudiera ser la que se apreciase más en los próximos años. Si embargo, si atendemos al origen de ésta crisis — exceso de deuda — y que Japón ha sido uno de los principales financiadores del proceso expansivo anterior, parece más viable que así sea.

\section{Conclusiones}

De las reflexiones que se han realizado anteriormente, podemos destacar que las hipotecas subprime han sido el punto más débil de un sistema excesivamente apalancado. Una vez que se inició la caída de este segmento del mercado de crédito, se pusieron en evidencia otras muchas debilidades del sistema. La falta de liquidez y de confianza amplificó la pérdida de solvencia de distintos agentes económicos, en particular de las entidades financieras.

La economía global avanza a una recesión como no se ha visto en décadas. Esto está provocando presión a la baja de los precios, que se mantendrán de medio plazo. Algunas economías, como la japonesa se verán inmersas en procesos deflacionarios.

El desapalancamiento supone deflación de activos reales y financieros. El entono de los mercados financieros estará condicionado por mayores primas de liquidez, plazo de 
la inversión y crédito, mientras se mantenga la inevitable reducción de deuda por parte de los agentes económicos.

\section{REFERENCIAS BIBLIOGRÁFICAS}

BANCO DE EsPAÑA, La financiación estructurada y las turbulencias financieras de 2007-2008. Introducción general, 2008.

BIS, BIS Quarterly Review, octubre y diciembre, 2008.

Federal Reserve, Senior Loan Officer Survey, enero, 2009.

Financial Stability Report Bank of England, octubre, 2008.

IMF, Global Financial Stability Report, octubre, 2008.

- World Economic Outlook, octubre, 2008.

Knop, R.; CAstro, M. de y Fernández, J. M., Manual de instrumentos de renta fija estructurados de tipos de interés y crédito, Ariel Economía, 2006.

Loeys, Jan, Investing in a Lower-Leverage Word: The View across Sectors and Asset Classes, JP Morgan, junio, 2008.

- How the Financial crisis will change markets, JP Morgan, abril, 2008.

Martínez-Abascal, E. y Guasch, J. Gestión de carteras de renta fija, McGraw-Hill Professional, 2002.

Policy lessons from the recent financial market turmoil, Hervé hannoun, BIS, mayo 2008. 